\title{
Thermo-Mechanical Optimization of Fixed Mask 2 for APS Front Ends
}

\author{
H. L. T. Nian, T. M. Kuzay, and I. C. A. Sheng
}

\section{DISCLAIMER}

This report was prepared as an account of work sponsored by an agency of the United States Government. Neither the United States Government nor any agency thereof, nor any of their employees, makes any warranty, express or implied, or assumes any legal liability or responsibility for the accuracy, completeness, or usefulness of any information, apparatus, product, or process disclosed, or represents that its use would not infringe privately owned rights. Reference herein to any specific commercial product, process, or service by trade name, trademark, manufacturer, or otherwise does not necessarily constitute or imply its endorsement, recommendation, or favoring by the United States Government or any agency thereof. The views and opinions of authors expressed herein do not necessarily state or reflect those of the United States Government or any agency thereof.

July 27, 1992

\section{Experimental Facilities Division Advanced Photon Source Argonne National Laboratory}

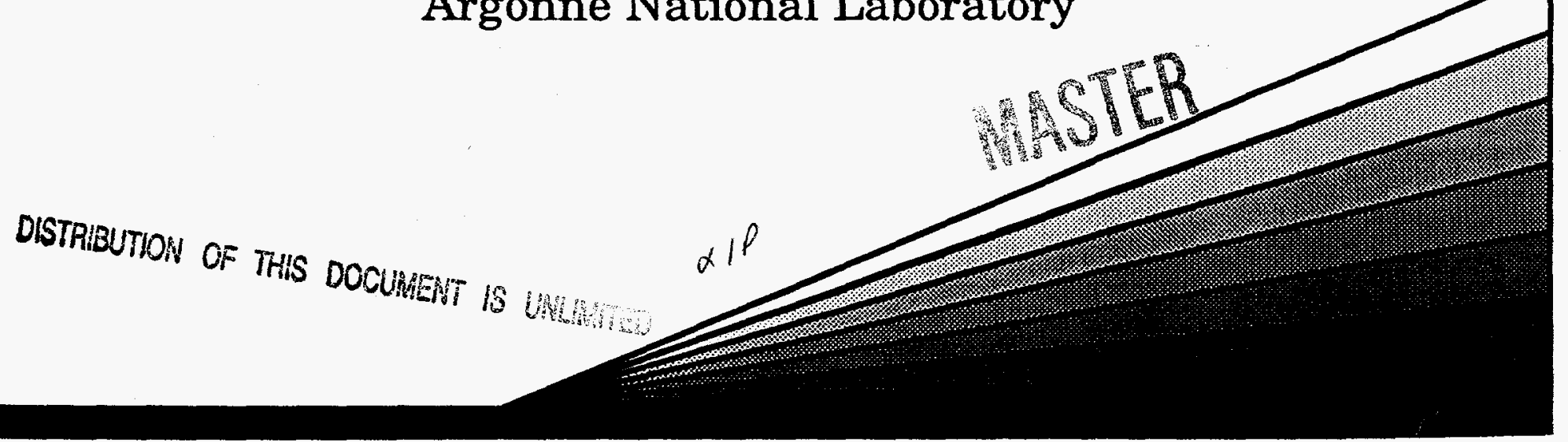




\section{DISCLAIMER}

Portions of this document may be illegible in electronic image products. Images are produced from the best available original document. 


\title{
Thermo-Mechanical Optimization of Fixed Mask 2 for APS Front Ends
}

H. L. Thomas Nian, Tuncer M. Kuzay, and I. C. Albert Sheng

Argonne National Laboratory

9700 S. Cass Ave., Argonne, IL 60439

\begin{abstract}
Fixed mask 2 (FM2) is one of the critical elements on the front end of the beamlines at the Advanced Photon Source (APS) now under construction at Argonne National Laboratory (ANL). The FM2 uses an enhanced heat transfer tube developed at ANL. Due to large thermal loads on these components, inclined geometry is used in the design to spread the footprint of the $x$-ray beam. Even then, thermal loads are very critical. To address the thermal and thermo-mechanical issues, analytical studies have been applied to a simplified model of the FM2 tube. The maximum temperature and maximum effective stress have been parametrically studied. Results for maximum temperatures and stresses are obtained and compared with the available strength/fatigue data for the materials proposed for the fixed mask design.
\end{abstract}

\section{Introduction}

Fixed Mask 2 (FM2) is one of the critical elements on the insertion device (ID) front end [1] of the beamlines at the Advanced Photon Source (APS) now under construction at Argonne National Laboratory (ANL). The FM2 uses an enhanced heat transfer tube developed at ANL [2]. Due to large thermal loads on these components, inclined geometry is used in the design to spread the footprint of the $\mathrm{x}$-ray beam. Even then, thermal loads are very critical. To address the thermal and thermo-mechanical issues, analytical studies [3] have been applied to a simplified model of the FM tube. The front-end design includes a pair of fixed masks (FM) and another pair of photon shutters (PS). The FMs contain the x-ray beam, whereas the PSs fully intercept it. However, both are designed to withstand the $x$-ray beam coming off the most powerful APS ID, currently, a $2.5 \mathrm{~m}$ long undulator designated Undulator A. The $2.5 \mathrm{~m}$ long Undulator $A$ has a total power of $5.2 \mathrm{~kW}$. Future plans for the APS include a $5 \mathrm{~m}$ long Undulator A with a total power of $10.4 \mathrm{~kW}$. This paper deals basically with $\mathrm{x}$-rays from the $2.5-\mathrm{m}$ ID. However, the analysis will be extended to the future 5-m device.

Research, development, and analysis on FMs and PSs have much in common. The FM and the PS share a similar flow tube that offers a highly enhanced heat transfer feature [2]. The FM is a box-like aperture with tapered vertical and horizontal sides. The sides are composed of the enhanced heat transfer tube set at small grazing angles to the beam. The PS, on the other hand, is built like a "hockey stick" coil set horizontally at a small grazing angle of 1.5 to 2 degrees to the beam. Therefore, the horizontal tubes of both the FM and the PS share the same analysis. The vertical tubes have less line density $\left(\frac{W}{\mathrm{~cm}}\right)$ heat flux than the horizontal tubes, thus, the resulting temperatures and stresses are smaller.

The high energy photon beam striking on these components will result in large temperature gradients and stresses. Therefore, it is necessary to analyze not only the tem- 
perature field but also the resulting thermal stresses. The x-ray beam has a complex profile, Gaussian in the vertical direction and parabolic in the horizontal direction as shown in Fig. 1 [4]. An analysis using the closed form solution has been carried out with a Gaussian beam profile spread in the horizontal plane at a grazing angle. An analysis using ANSYS-applied real-beam-profile strikes on these component was carried out to verify the analytical solution.

Both Glidcop [5] and oxygen-free copper (OFC) are used to build the structures of these components. Glidcop has much better fatigue strength above $150^{\circ} \mathrm{C}$ than does OFC [6]. The purpose of using a Glidcop plate is to let the beam strike the Glidcop surface, while the OFC acts as a cooling sub-structure. (The Glidcop plate is bonded to the OFC sub-structure.)

\section{Nomenclature}

\begin{tabular}{|c|c|}
\hline $\mathrm{T}:$ & Temperature $\quad\left({ }^{\circ} \mathrm{C}\right)$ \\
\hline$\sigma_{i j}:$ & Stress Component \\
\hline k: & Thermal Conductivity $\quad\left(\mathrm{W} / \mathrm{m} \cdot{ }^{\circ} \mathrm{C}\right)$ \\
\hline XYZ: & Fixed Coordinate \\
\hline q: & Heat Flux $\quad\left(W / m^{2}\right)$ \\
\hline t: & Thickness of Plate \\
\hline h: & Convective Heat Transfer Coefficient \\
\hline $\mathrm{T}_{\infty}:$ & (assumed to be $32.2^{\circ} \mathrm{C}$ ) \\
\hline l: & Length of the Plate ( $\mathrm{m})$ \\
\hline b: & Width of the Plate ( $\mathrm{m})$ \\
\hline a: & Width where q Applied to Absorber \\
\hline$r_{0}$ & Standard Deviation ( $\mathrm{m}$ ) \\
\hline$\nu:$ & Poisson's Ratio \\
\hline$\alpha_{t}:$ & Thermal Expansion Coefficient \\
\hline
\end{tabular}

\section{Analytical Solution}

A closed form analytical solution was developed for a simplified model using a Gaussiandistributed heat flux. The channel tube is stretched into a plate, keeping the water-cooled area constant [2]. The thermal-analytical model can be applied to any thermal beam. In the following section, the energy equation, boundary conditions, and solution are described. The model does provide a good approximation for the channel tube. Consequently, the thermal stress and the deformation can also be expressed and approximated in closed form. From these equations, we can follow parametrically the trend of the thermal gradient and the thermal stress due to the temperature field created by the beam. 


\subsection{Temperature Field}

A two-dimensional, steady-state boundary value problem was assumed in our analysis [3]. Because properties of Glidcop and OFC are similar, we assumed they are a single material. Hence, the heat equation is

$$
\frac{\partial^{2} T}{\partial x^{2}}+\frac{\partial^{2} T}{\partial y^{2}}=0
$$

The boundary conditions are

$$
\begin{array}{ll}
-k \frac{\partial T}{\partial y}(x, 0)=q_{o} \exp \left(-\frac{x^{2}}{r_{o}^{2}}\right) & 0 \leq x \leq a . \\
-k \frac{\partial T}{\partial y}(x, 0)=0 & a<x \leq b \\
-k \frac{\partial T}{\partial y}(x, t)=h_{c}\left(T-T_{\infty}\right) & \\
\frac{\partial T}{\partial x}(0, y)=\frac{\partial T}{\partial x}(b, y)=0 . &
\end{array}
$$

The solutions give

$$
\theta=C_{o}\left[\eta-1-\frac{1}{B i}\right]+\sum_{m=1}^{\infty} C_{m} e^{-\lambda_{m} \eta} \cos \left(\lambda_{m} \xi\right)\left[1+\frac{\lambda_{m}-B i}{\lambda_{m}+B i} e^{2 \lambda_{m}(\eta-1)}\right],
$$

where

$$
\begin{gathered}
\alpha=\frac{a}{t}, \quad \beta=\frac{b}{t}, \quad \xi=\frac{x}{t} \\
\eta=\frac{y}{t}, \quad \theta=\frac{k\left(T-T_{\infty}\right)}{q t}, \quad B i=\frac{h_{c} t}{k}, \\
C_{o}=-\frac{r \sqrt{\pi}}{2 \alpha} \operatorname{erf}\left(\frac{\alpha}{r}\right),
\end{gathered}
$$

where $\operatorname{er} f(.$.$) is known to be the error function defined by [7] and$

$$
C_{m}=-\frac{\sqrt{\pi} r \exp \left(-\frac{r^{2} \lambda_{m}^{2}}{4}\right) \operatorname{Re}\left[\operatorname{erf}\left(\frac{2 \alpha+i r^{2} \lambda_{m}}{2 r}\right)\right]}{\lambda_{m} \alpha\left(-1+e^{-2 \lambda_{m}} \frac{\lambda_{m}-B i}{\lambda_{m}+B i}\right)}, \quad \lambda_{m}=\frac{m \pi}{\beta}, \quad m \in N .(6)
$$

$\operatorname{Re}(z)$ is the real part of the complex variable $z ; i$ is the imaginary number defined by $\sqrt{-1}=i$. 


\subsection{Stress Field}

The magnitude of the cross section ( $x y$ plane) of the fixed mask is much smaller than that of the length ( $z$ axis). Therefore the fixed mask behaves as a thermoelastic beam that is subject only to thermal loading.

The practical analysis of elastic beams under thermal loading is usually performed under Bernoulli-Euler rules [7]. That is, sections that are plane and perpendicular to the axis before loading remain so after loading, and the effect of lateral contraction may be neglected. The only nonzero stress component is $\sigma_{z z}$, which satisfies [7]:

$$
\left(\frac{\partial^{2}}{\partial \xi^{2}}+\frac{\partial^{2}}{\partial \eta^{2}}\right)\left(\bar{\sigma}_{z z}+\gamma \theta\right)=0
$$

where

$$
\bar{\sigma}_{z z}=\frac{\sigma_{z z}}{E}, \quad \gamma=\frac{\alpha_{t} q t}{k}
$$

For any cross section, the total force and moments have to be in equilibrium. That is,

$$
\int \sigma_{z z} d A=\int \sigma_{z z} \xi d A=\int \sigma_{z z} \eta d A=0
$$

where $\int \ldots d A$ denotes the area integral over the cross section.

From Eq. (7), the general solution is

$$
\bar{\sigma}_{z z}=-\gamma \theta+k_{0}+k_{1} \xi+k_{2} \eta
$$

where

$$
k_{0}=7 a_{0}-3 a_{1}-3 a_{2}, \quad k_{1}=-\frac{6 a_{0}-6 a_{1}}{\alpha}, \quad k_{2}=-6 a_{0}-6 a_{2} \text {, }
$$

and

$$
\begin{aligned}
a_{0}= & \frac{\gamma r \sqrt{\pi}}{2 \alpha}\left(\frac{1}{2}+\frac{1}{B i}\right) \operatorname{erf}\left(\frac{\alpha}{r}\right) \\
a_{1}= & \frac{\gamma r \sqrt{\pi}}{2 \alpha}\left(\frac{1}{2}+\frac{1}{B i}\right) \operatorname{erf}\left(\frac{\alpha}{r}\right)-\frac{4 \gamma r \sqrt{\pi}}{\alpha^{3}} \\
& \sum_{m=1,3,5, . .}^{\infty} \frac{\exp \left(-\frac{r^{2} \lambda_{m}^{2}}{4}\right) \operatorname{Re}\left[\operatorname{erf}\left(\frac{2 \alpha+i r^{2} \lambda_{m}}{2 r}\right)\right]}{\lambda_{m}^{4}}\left(1-\frac{2 B i e^{-\lambda_{m}}}{\left(\lambda_{m}+B i\right)-e^{-2 \lambda_{m}\left(\lambda_{m}-B i\right)}}\right) \\
a_{2}= & \frac{\gamma r \sqrt{\pi}}{2 \alpha}\left(\frac{1}{3}+\frac{1}{B i}\right) \operatorname{erf}\left(\frac{\alpha}{r}\right) .
\end{aligned}
$$

For more details about the analysis please refer to [3]. 


\section{Numerical Solution}

A three-dimensional finite element analysis was carried out to verify the closed form solution for APS front-end components. The convective heat transfer coefficient has a minimum value of $3 \frac{W}{\mathrm{~cm}^{2}} \cdot{ }^{\circ} \mathrm{C}[2]$, which is used in the finite element code ANSYS to verify the results from the closed form.

\section{Results and Discussion}

The parameters that are used in the analysis are as follows:

\begin{tabular}{lll}
\hline & $\ddots$ & \\
The Power from 2.5-m Undulator A & $Q$ & $-5000 \mathrm{~W}$ \\
Conductivity of Glidcop & $K$ & $365 \mathrm{~W} /\left(\mathrm{m}^{\circ} \mathrm{C}\right)$ \\
Conductivity of OFC & $K$ & $391 \mathrm{~W} /\left(\mathrm{m}^{\circ} \mathrm{C}\right)$ \\
Young's Modulus of Glidcop & $E$ & $1.3 \times 10^{5} \mathrm{MPa}$ \\
Young's Modulus of OFC & $E$ & $1.15 \times 10^{5} \mathrm{MPa}$ \\
Thermal Exp. Coef. of Glidcop & $\alpha$ & $16.6 \times 10^{-6} \frac{1}{\circ^{\circ} \mathrm{C}}$ \\
Thermal Exp. Coef. of OFC & $\alpha$ & $17.7 \times 10^{-6} \frac{1}{{ }^{\circ} \mathrm{C}}$ \\
Poisson Ratio (Closed Form) & $\nu$ & 0 \\
Poisson Ratio of Glidcop & $\nu$ & .33 \\
Poisson Ratio of OFC & $\nu$ & .343 \\
Incident Beam Angle & $\theta$ & $2^{\circ}$ \\
Distance from the Source & $l$ & $20.3 \mathrm{~meter}$ \\
Peak Power & $q_{0}$ & $14 \frac{\mathrm{W}}{\mathrm{mm}^{2}}$ \\
& &
\end{tabular}

The x-ray beam has a complex profile, Gaussian in the vertical direction and parabolic in the horizontal direction. In order to use the closed form solution described above, we have to fit the beam power (shown in Fig. 1), which strikes the FM2, to a Gaussian-distributed heat flux. By using the least squares method, we found the standard deviation for the power at different distances and angles.

Figures 2 and 3 show the maximum temperature on the heating surface and cooling channel wall of the Glidcop material, respectively. From Fig. 2, we note that the maximum temperature has an optimal value. For example, for $h=3 \frac{W}{\mathrm{~cm}^{2}{ }^{\circ} \mathrm{C}}$, the optimal thickness is $5 \mathrm{~mm}$ to obtain a minimum surface temperature of about $223^{\circ} \mathrm{C}$. Lower temperatures can only be obtained with higher " $h$ " above $3 \frac{W}{\mathrm{~cm}^{2}{ }^{\circ} \mathrm{C}}$. From Fig. 3, it is seen that, under these conditions, the maximum cooling channel temperature will be about $130^{\circ} \mathrm{C}$. Increasing the channel wall thickness (Glidcop plus OFC) from $5 \mathrm{~mm}$ to $10 \mathrm{~mm}$ will help reduce the 
cooling channel wall temperature to $95^{\circ} \mathrm{C}$, while keeping the maximum temperature about the same $\left(229^{\circ} \mathrm{C}\right)$.

The effective stress from the closed form solution was calculated based on the assumption that the tube was stretched into a flat plate. Figure 4 shows the maximum effective stress on the Glidcop surface. The slope of the maximum effective stress curves matches the maximum temperature curves as expected.

Interfacial stress calculations for the closed form are addressed next. Calculation of the stress at the bonding surface was based on a single material. Normally, stress discontinuity will occur at the bonding surface due to differences in material properties, such as the thermal expansion coefficients and Young's moduli. It is tedious to derive solutions to reconcile discontinuity in stress at the bonding surface. Figure 6 shows the trend of the stress at the bonding surface if both materials have exactly the same properties. Note that, in the closed form solution for two layer materials, the interface is expected to have higher stress than that presented here.

Table 1: FM2, $h=3 \frac{W}{\mathrm{~cm}^{2}{ }^{\circ} \mathrm{C}}, 5 \mathrm{Kw}$

\begin{tabular}{|l|c|c|c|c|c|c|}
\hline & \multicolumn{3}{|c|}{$\begin{array}{c}\text { Closed Form } \\
\text { (Curve-Fit Gaussian Profile) }\end{array}$} & \multicolumn{3}{c|}{$\begin{array}{c}\text { ANSYS } \\
\text { (Real Beam Profile) }\end{array}$} \\
\hline Thickness of Glidcop $m m$ & $\mathrm{t}=3.175$ & $\mathrm{t}=4.5$ & $\mathrm{t}=6.35$ & $\mathrm{t}=3.175$ & $\mathrm{t}=4.5$ & $\mathrm{t}=6.35$ \\
\hline $\begin{array}{l}\text { Max. Temperature } \\
\text { on the surface }\left({ }^{\circ} \mathrm{C}\right)\end{array}$ & 224 & 225 & 227 & 208 & 208 & 206 \\
\hline $\begin{array}{l}\text { Max. Temperature } \\
\text { on the cooling channel }\left({ }^{\circ} \mathrm{C}\right)\end{array}$ & 120 & 114 & 100 & 105 & 93 & 82 \\
\hline $\begin{array}{l}\text { Max. Effective Stress } \\
\text { on Glidcop surface (MPa) }\end{array}$ & 270 & 275 & 280 & 270 & 265 & 256 \\
\hline $\begin{array}{l}\text { Max. Temperature } \\
\left.\text { on the bonding surface ( }{ }^{\circ} \mathrm{C}\right)\end{array}$ & 148 & 135 & 120 & 145 & 122 & 104 \\
\hline $\begin{array}{l}\text { Max. Effective Stress on } \\
\text { the bonding surface (MPa) }\end{array}$ & 130 & 90 & 60 & 155 & 110 & 85 \\
\hline
\end{tabular}

The FM2 of the front end is made of two different materials, Glidcop and OFC. Glidcop has much better strength above $150^{\circ} \mathrm{C}$. The purpose of using a Glidcop plate is to allow the beam to strike the Glidcop surface; the OFC acts as the cooling sub-structure. Figs. 5 and 6 show the maximum temperature and maximum effective stress, respectively, at the bonding surface for a $3.175 \mathrm{~mm}$ thick OFC tube. Copper sponge is brazed to the inside of the OFC tube, and a Glidcop face plate is bonded to the outside surface of the OFC. During the brazing/bonding process, the tensile strength of OFC drops. Figures 7 and 8 show the softening curves for OFC. It is, therefore, worthwhile to optimize the Glidcop thickness to reduce the maximum effective stress of OFC to a minimum when the beam strikes. Because thermal fatigue data on the OFC are not available at this time, it is 
desirable to keep the temperature and thermal stress low to attain a safety factor of 4 or better without considering the thermal fatigue in OFC. For example, for $h=3 \frac{W}{\mathrm{~cm}^{2}{ }^{\circ} \mathrm{C}}$ with a $3 \mathrm{~mm}$ thick OFC tube, increasing the thickness of Glidcop from $3 \mathrm{~mm}$ to $6 \mathrm{~mm}$ decreases the maximum temperature at the bonding surface from $150^{\circ} \mathrm{C}$ to $120^{\circ} \mathrm{C}$.

The maximum temperature and effective stress were not calculated for vertical tubes of the FM2, because the line density at any cross section is smaller [3]. This can easily be seen by the fitting curve; for horizontal tubes, the standard deviation $r_{o}$ is $.19 \mathrm{~cm}$; for vertical tubes, the standard deviation $r_{o}$ is $.073 \mathrm{~cm}$.

Table 1 lists the comparative results between the closed form and ANSYS solutions. Both methods agree within $5 \%$. The optimized values of maximum stress show some discrepancies due to the difference between the real beam profile (ANSYS) and a curve-fit Gaussian profile (closed form). Nevertheless, the trend from ANSYS is such that the thicker the layer of Glidcop, the lower the maximum effective stress will be when the real beam profile is used. The total material thickness is kept between $6.25 \mathrm{~mm}$ to $9.5 \mathrm{~mm}$ for the ANSYS calculations.

\section{Conclusion}

From Table 1, we know that the maximum effective stress at the Glidcop surface is about $270 \mathrm{MPa}$ regardless of the total thickness. Figure 10 shows the softening resistance of Glidcop AL-15 versus that of OFC and zirconium copper. The Glidcop face plate of FM2 has a safety factor about 2 without considering thermal fatigue. Currently, research in this area shows that Glidcop can be subjected to high temperature $\left(870^{\circ} \mathrm{C}\right)$ braze thermal cycles without damage. Figure 11 shows the tensile properties of Glidcop AL-15 under braze thermal cycles [6]. According to Fig. 11, the Glidcop face plate has at least a safety factor of 1.5 under thermal cycles because our maximum temperature (about $208{ }^{\circ} \mathrm{C}$ ) is much lower than $870{ }^{\circ} \mathrm{C}$.

The safety factor related to bonding and the OFC tube is not an issue if we can optimize the Glidcop thickness as described above.

\section{Acknowledgments}

Acknowledgement: This work was supported by the U.S. Department of Energy, BESMaterials Science, under contract W-31-109-Eng-38. 


\section{References}

[1] D. Shu, J. Barraza, T. Sanchez, R. W. Nielsen, J. T. Collins, and T. M. Kuzay. Front End Designs for the $7 \mathrm{GeV}$ Advanced Photon Source Nuclear Instruments and Methods in Physics Research, in press, Apr. 1992, also 7th Nat. Conf. on SRI, Baton Rouge, LA (Oct 28-31,1991)

[2] Tuncer M. Kuzay. Fixed Mask Assembly Research for APS Insertion Devices. ANL $90 / 20,1990$

[3] H.L. Nian, I.C. Albert Sheng and Tuncer M. Kuzay. Thermal Analysis of a Photon Shutter for APS Front Ends, Nuclear Instruments and Methods in Physics Research, in press, Apr. 1992, also 7th Nat. Conf. on SRI, Baton Rouge, LA (Oct 28-31,1991)

[4] G. K. Shenoy, P. J. Viccaro, and D. M. Mills. Characteristics of the 7-GeV Advanced Photon Source: a Guide for Users. ANL - 88/9, 1988

[5] SCM Metal Products, Inc. Glidcop Grade AL-15 Dispersion Strengthened Copper

[6] J. J. Stephens, and D. T. Schmale. The Effect of High Temperature Braze Thermal Cycles on Mechanical Properties of a Dispersion Strengthened Copper Alloy. SAND87$1296 \cdot$ UC-20

[7] M. Abramowitz and I. A. Stegum, Handbook of Mathematical Functions, p.228, Dover Publications, Inc., 1965

[8] J. H. Weiner and B. A. Boley. Theory of Thermal Stresses. New York, Wiley, 1923 
|

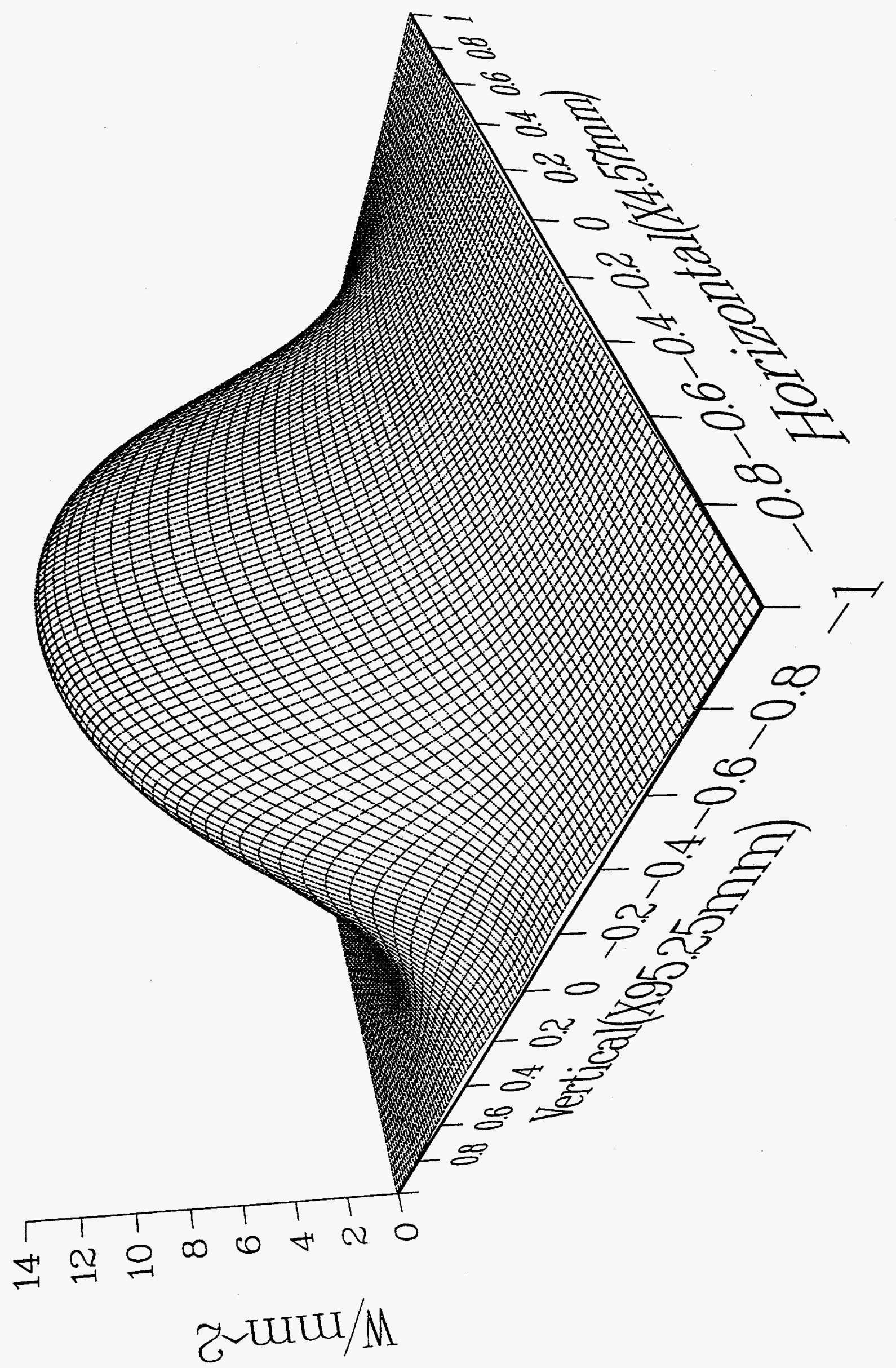


Figure 2: Maximum Surface Temperature for Glidcop (FM2)

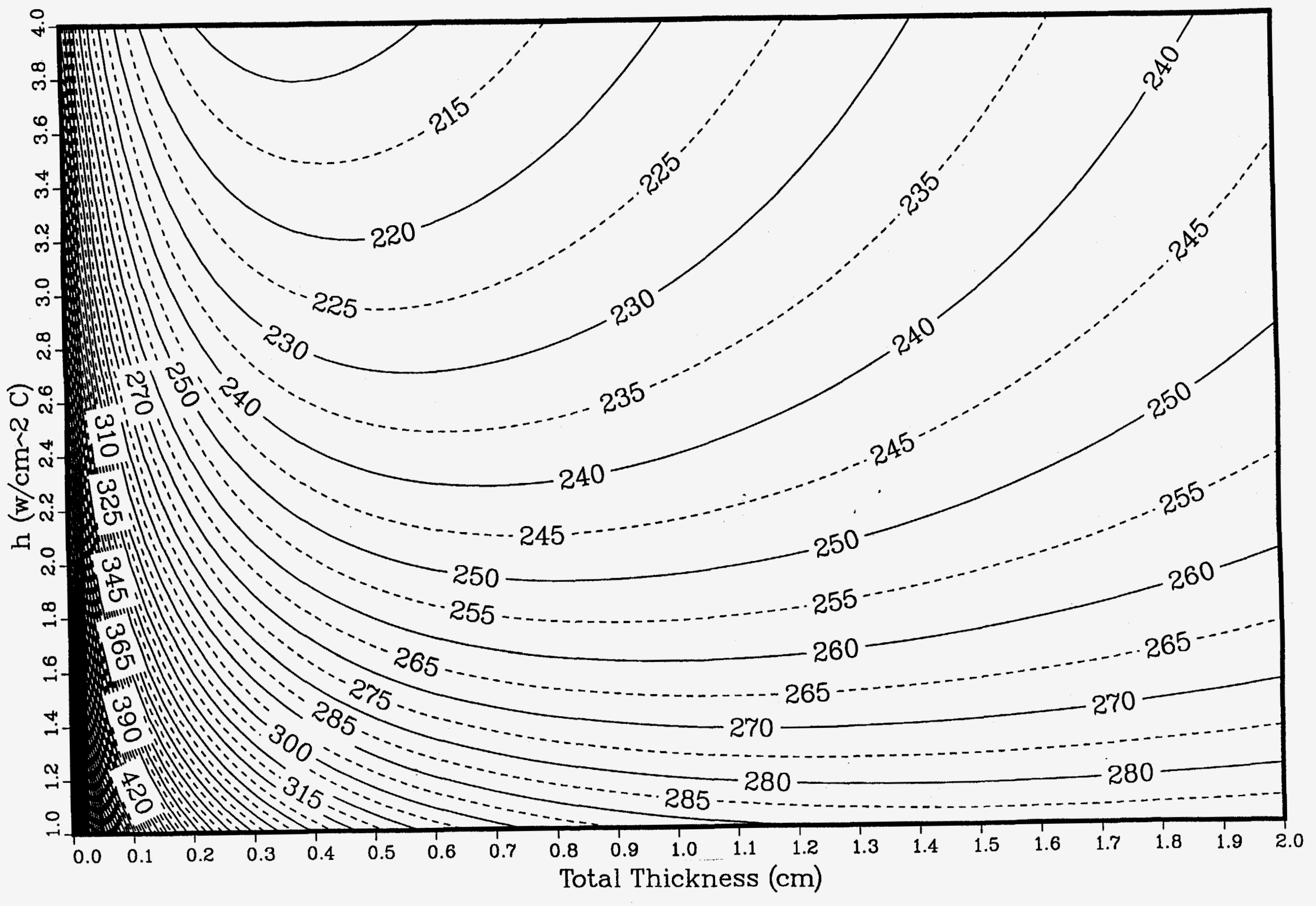




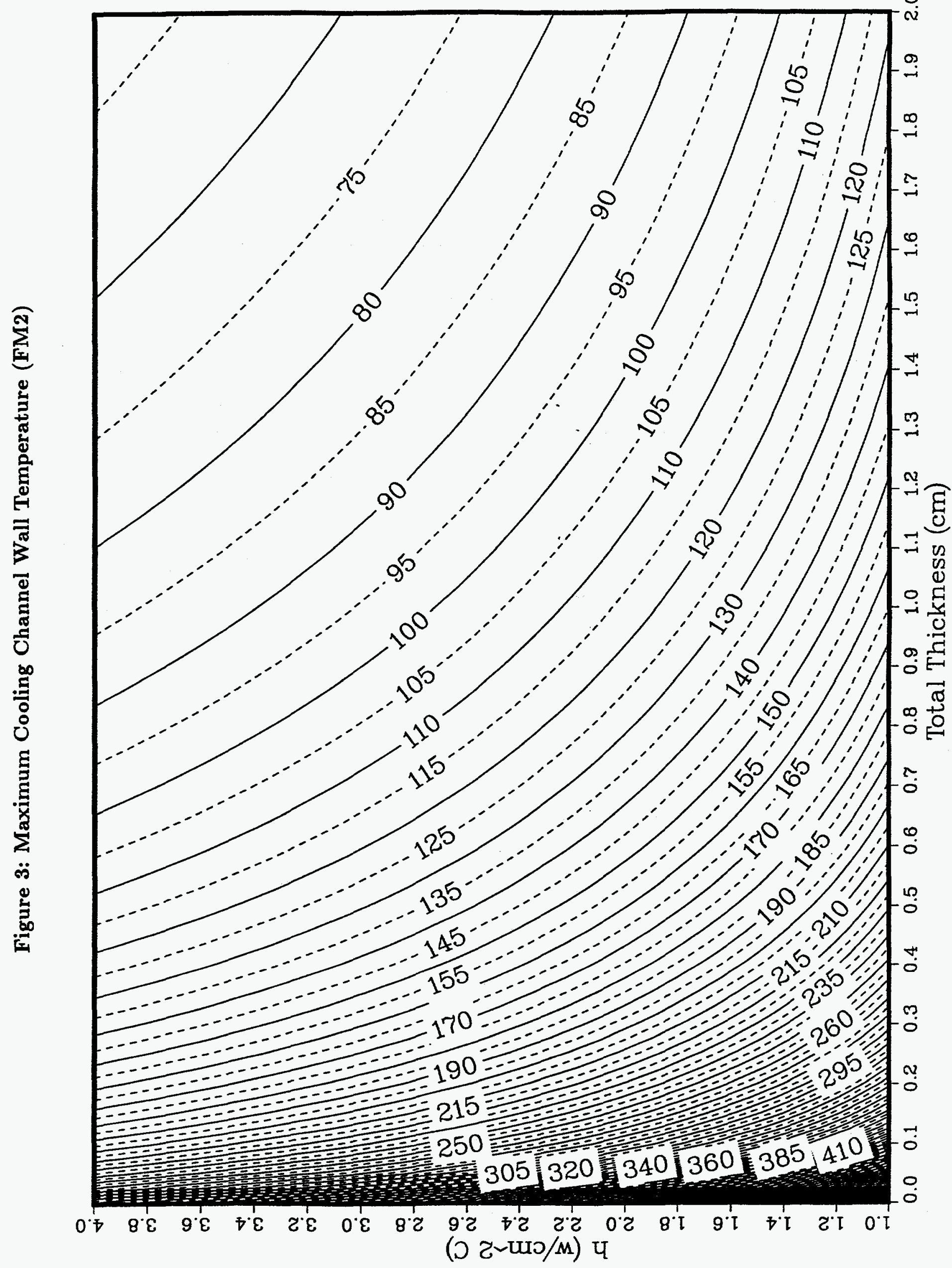


$\mathrm{h}(\mathrm{w} / \mathrm{cm} \sim 2 \mathrm{C})$

$\begin{array}{llllllllllllllll}1.0 & 1.2 & 1.4 & 1.6 & 1.8 & 2.0 & 2.2 & 2.4 & 2.6 & 2.8 & 3.0 & 3.2 & 3.4 & 3.6 & 3.8 & 4.0\end{array}$

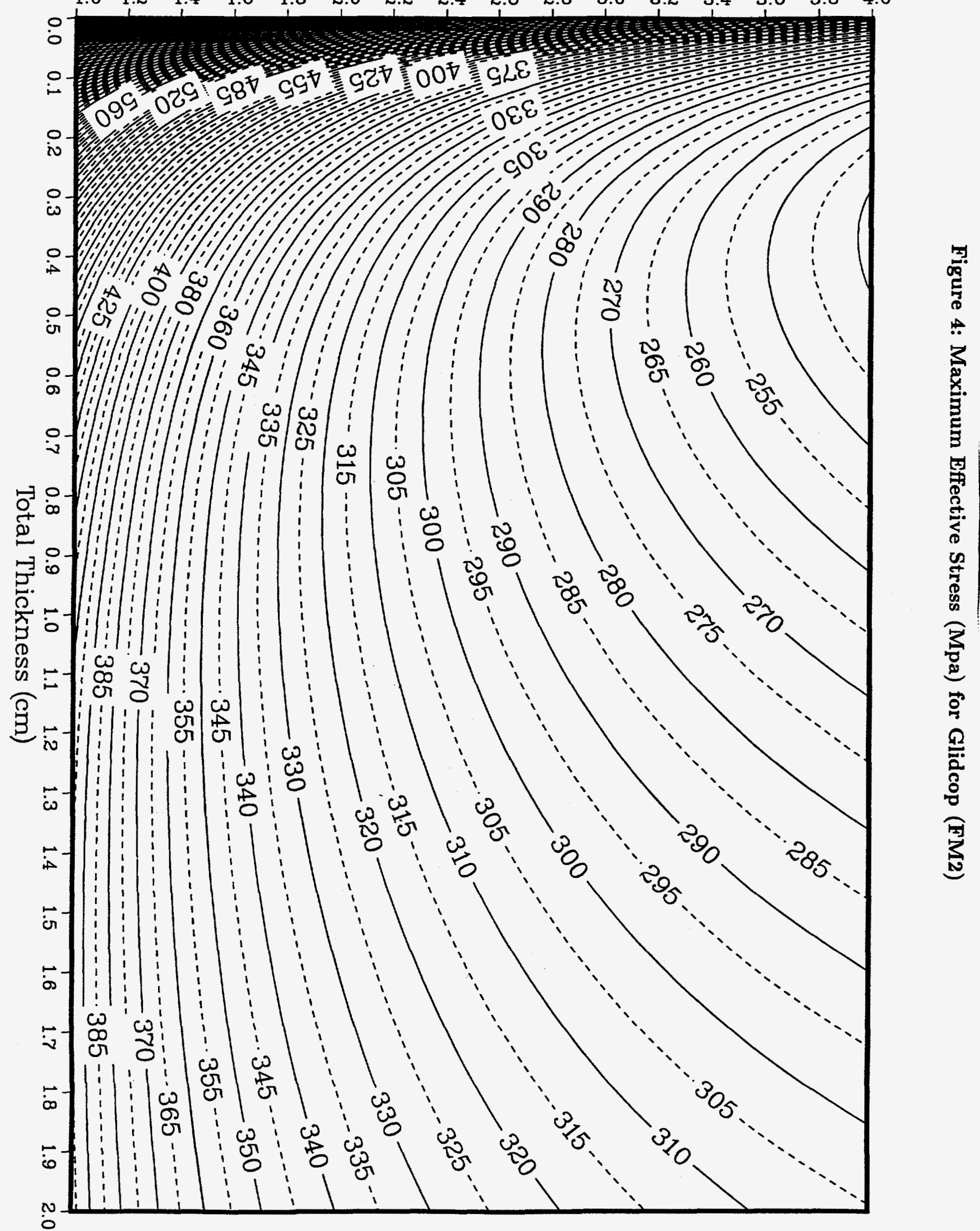




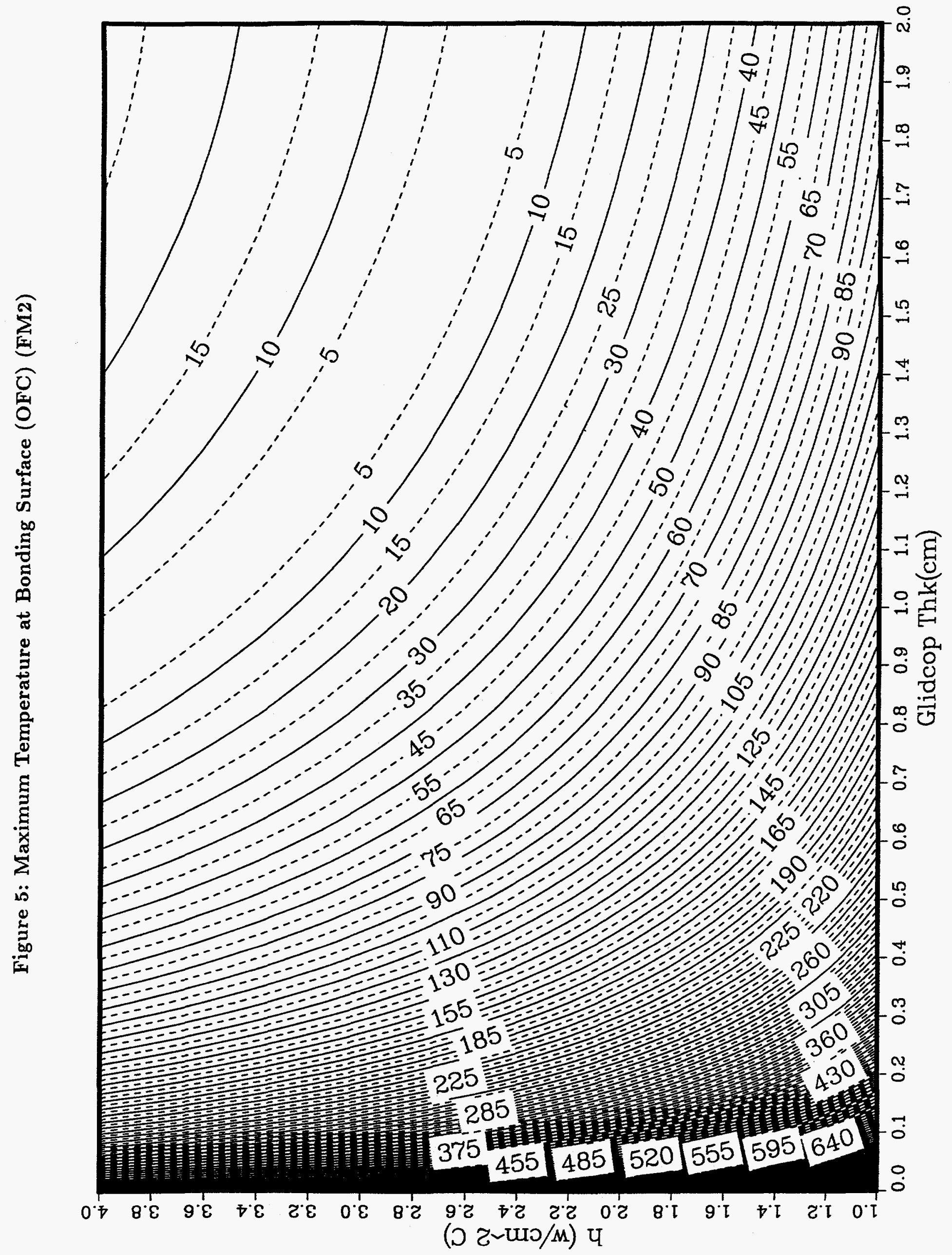


Figure 6: Maximum Effective Stress at Bonding Surface (OFC) (FM2)

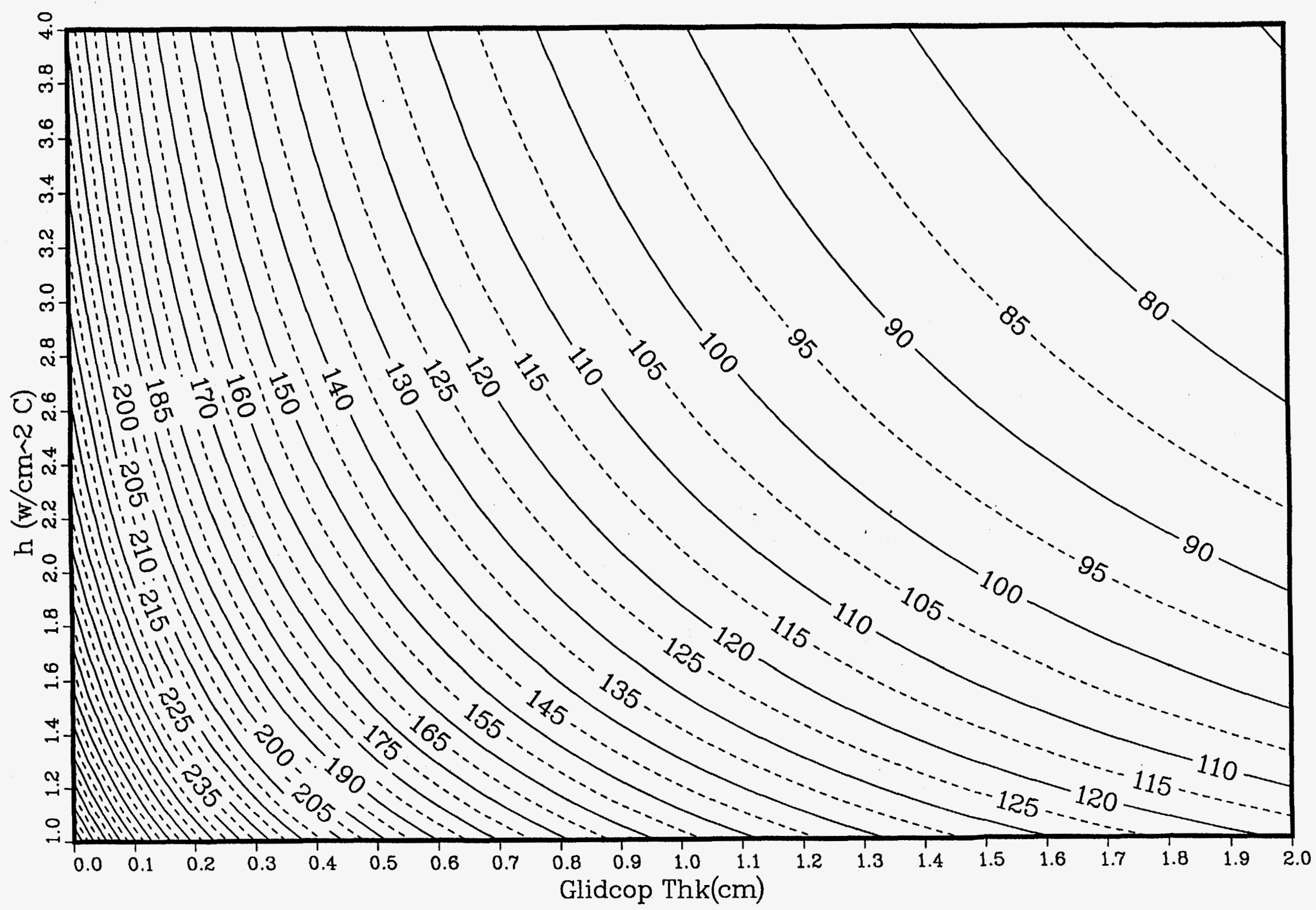


Figure 7: Isothermal Softening Curves for OFC, SN-OFC and Ag-OFC

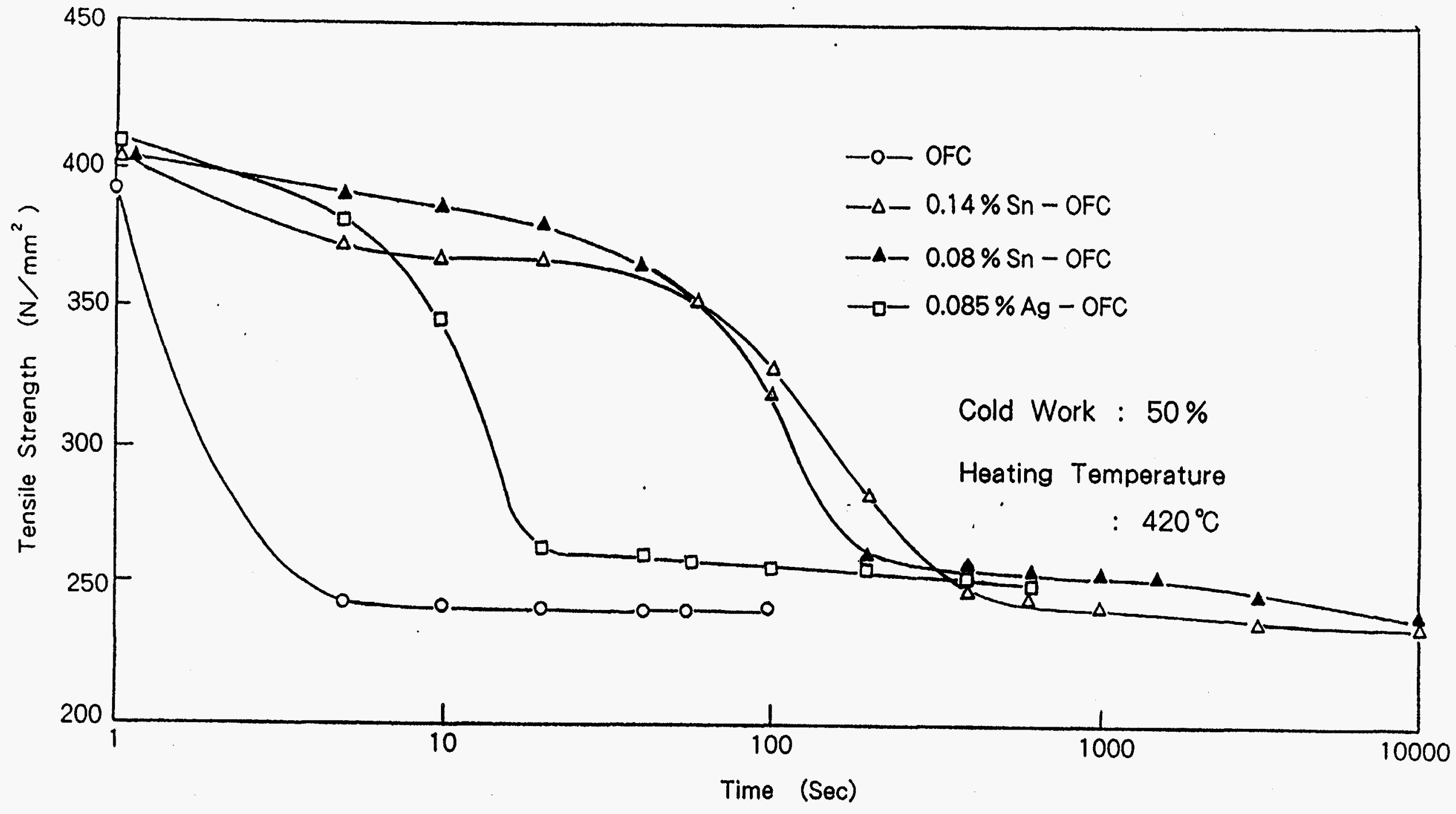




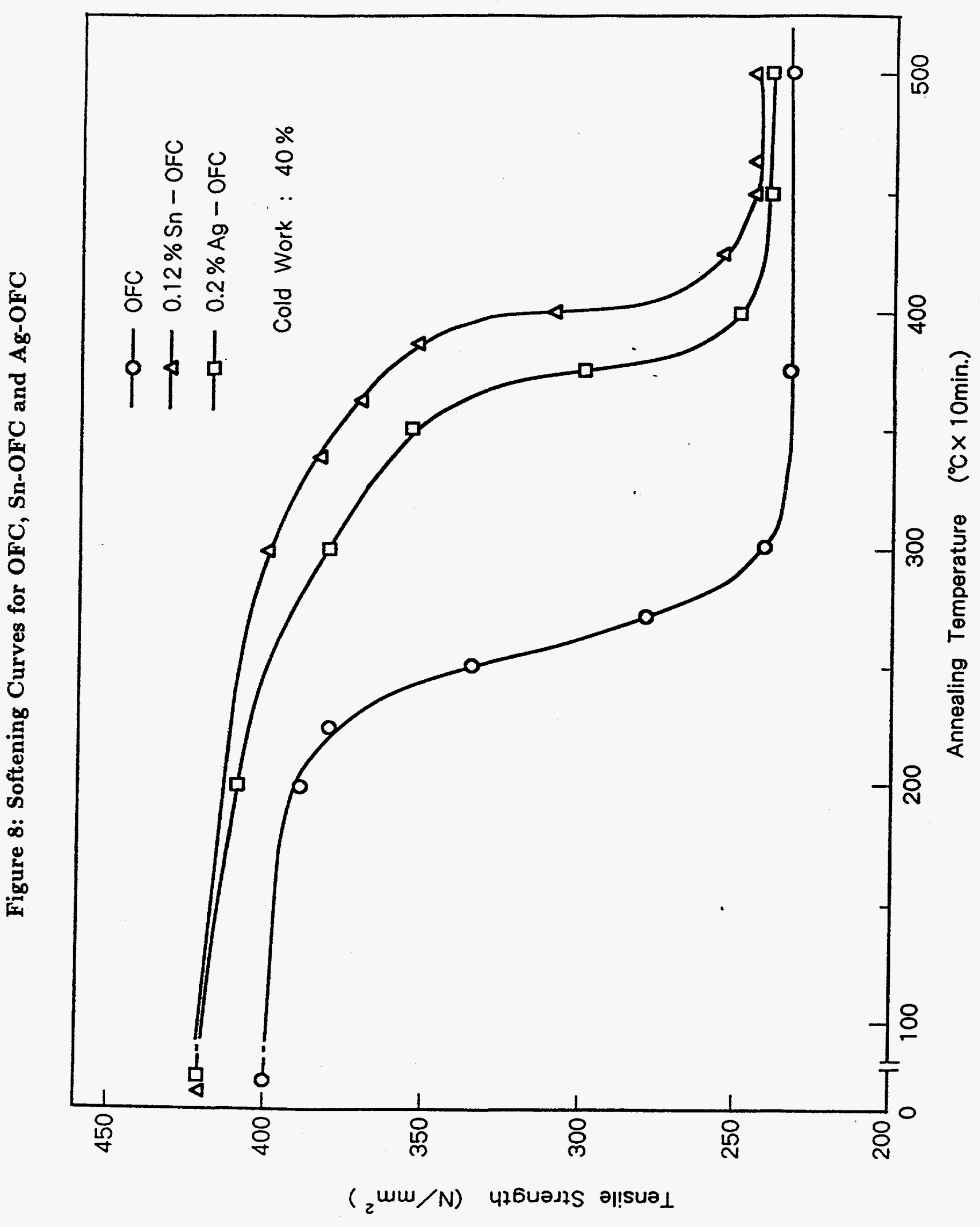




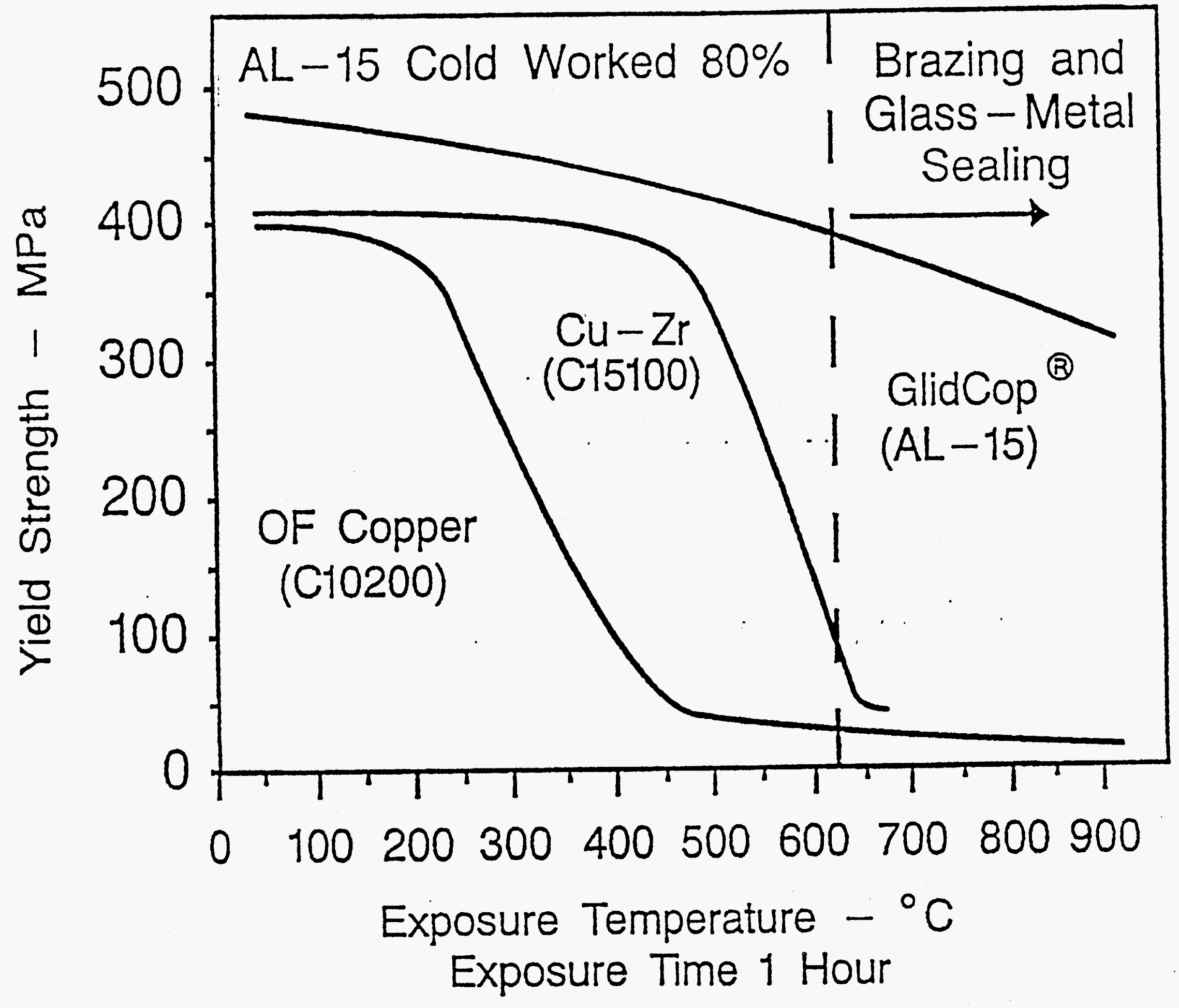


Figure 10: Room Temperature Tensile Properties of AL-15 Tube Specimens Subjected to A Standard (5 Minute at $870^{\circ} \mathrm{C}$ ) Ticusil Braze Cycle Compared to Cold-Worked AL-15.

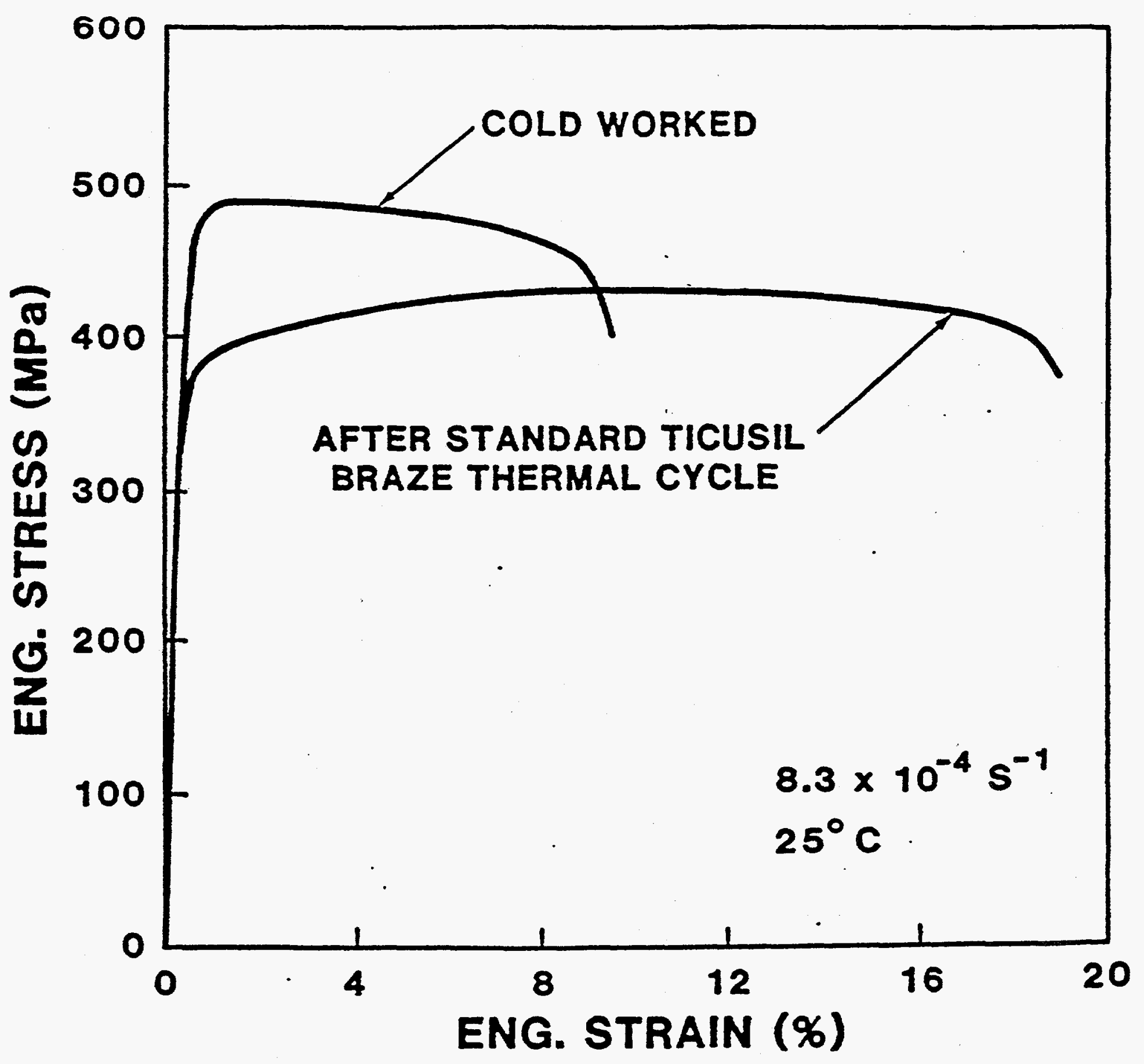

